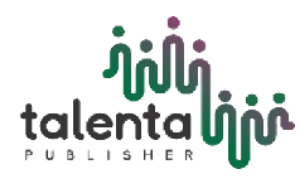

Jurnal Dinamis

Vol. 9, No. 1, Bulan Tahun | 06-21

ISSN : 0216-7492, e-ISSN : 2809-3410

Homepage : https://talenta.usu.ac.id/dinamis

\title{
ANALISIS KARAKTERISTIK VIBRASI PADA CASING BAGIAN TRANSMISI SLUDGE SEPERATOR DENGAN FEA
}

\author{
Donal Fresly P Napitupulu ${ }^{*}$, Muhammad Sabri ${ }^{2}$, Prakarsa A P Surbakti ${ }^{3}$ \\ Departemen Teknik Mesin, Fakultas Teknik, Universitas Sumatera Utara \\ Jalan Dr. T. Mansyur No. 9, Padang Bulan, Kec. Medan Baru, Kota Medan, Sumatera Utara 20222, Indonesia \\ *Email: Donalnapit16@gmail.com
}

\begin{abstract}
ABSTRAK
Transmisi (sludge separator) berfungsi untuk memindahkan dan mengubah tenaga dari motor yang berputar, yang digunakan untuk memutar roda gigi (worm gear) pada sludge separator poros yang menuju bowl disck. Tingkat getaran yang terjadi dalam transmisi sangat penting agar tidak terjadi kegagalan. Tujuan penelitian yaitu untuk mengetahui fenomena getaran dan mode getaran yang terjadi pada transmisi. Material dan kondisi batas yang digunakan mempengaruhi frekuensi natural dan mode getaran yang terjadi. Metode yang akan digunakan dalam analisis getaran ini adalah dengan menggunakan analisis modal berdasarkan FEA. Perangkat lunak digunakan dalam membangun bentuk CAD dan proses FEA. Model numerik bercirikan matriks kekakuan struktur dibangun untuk menyelidiki getaran transmisi beserta casing. Hasil yang didapatkan pada penelitian ini yaitu frekuensi natural pada casing sludge separator percobaan pertama $(138,26-366,14) \mathrm{Hz}$, percobaan kedua $(139,45-675,54) \mathrm{Hz}$, percobaan ketiga $(243,65-761,10) \mathrm{Hz}$, percobaan keempat $(243,64-764,67) \mathrm{Hz}$, percobaan kelima $(243,75-786,34) \mathrm{Hz}$, percobaan ke enam $(243,75-786,34) \mathrm{Hz}$, pada penelitian ini didapatkan frekuensi natural terkecil terjadi pada percobaan pertama yaitu $138,26 \mathrm{~Hz}$, sedangkan frekuensi natural terbesar terbesar pada percobaan keenam 786,34 Hz. Hal ini terjadi dikarenakan hubungan kontak yang terjadi pada percobaan ke enam diberikan rpm lebih besar yaitu $6500 \mathrm{rpm}$ sehingga kontak antar roda gigi lebih besar dan menghasilkan frekuensi natural yang lebih besar.
\end{abstract}

Kata kunci: Transmisi (worm gear), Casing, Frekuensi Natural, Analisis Modal, Mode Getar, FEA

\begin{abstract}
The transmission (sludge separator) functions to move and change the power from the rotating motor, which is used to rotate the gear (worm gear) on the shaft sludge separator leading to the bowl disck. The level of vibration that occurs in the transmission is very important so that failure does not occur. The research objective is to determine the phenomena of vibration and vibration modes that occur in transmission. The material and boundary conditions used affect the natural frequency and mode of vibration that occurs. The method to be used in this vibration analysis is to use modal analysis based on the FEA. Software is used in building CAD forms and in the FEA process. A numerical model characterized by a structural stiffness matrix was constructed to investigate the transmission vibration and the casing. The results obtained in this study are the natural frequency in the casing of the sludge separator, the first experiment $(138,26-366,14) \mathrm{Hz}$, the second experiment $(139,45-675,54) \mathrm{Hz}$, the third experiment $(243,65-761,10) \mathrm{Hz}$, fourth experiment $(243.64$ 764.67) $\mathrm{Hz}$, fifth experiment $(243.75-786.34) \mathrm{Hz}$, sixth experiment $(243.75-786.34) \mathrm{Hz}$, in this study the smallest natural frequency occurs in the first experiment, it was $138.26 \mathrm{~Hz}$, while the largest natural frequency was in the sixth experiment, $786.34 \mathrm{~Hz}$. This happens because the contact relationship that occurs in the sixth experiment is given a greater rpm, namely 6500 rpm so that the contact between the gears is greater and produces a greater natural frequency.
\end{abstract}

Keywords: transmission (worm gear), casing, natural frequency, modal analysis, mode of vibration, FEA

\section{PENDAHULUAN}

Seiring Kelapa sawit (Elaeis) adalah tumbuhan industri penting penghasil minyak masak, minyak industri, maupun bahan bakar (biodiesel). Perkebunannya menghasilkan keuntungan besar sehingga banyak hutan dan perkebunan lama dikonversi menjadi perkebunan kelapa sawit. Di Indonesia penyebaran kebun kelapa sawit meliputi daerah Aceh, pantai timur Sumatra, Jawa, Kalimantan, dan Sulawesi. Kelapa sawit menjadi salah satu komoditas yang bernilai tinggi. Indonesia adalah salah satu negara yang mampu menyediakan kebutuhan minyak sawit dunia, angkanya bahkan bisa mencapai 80 persen dari kebutuhan global. Bisnis di bidang kelapa sawit tumbuh pesat ke arah yang positif bukan 
tanpa alasan, permintaan olahan kelapa sawit berupa crude palm oil atau CPO yang terus meningkat setiap tahunnya menjadi faktor utama yang membuatnya terus berkembang.

Fungsi dari Sludge Seperator / Low Speed Sludge Centrifuge adalah untuk mengambil minyak yang masih terkandung dalam sludge dengan prinsip gaya sentrifugal. Dengan gaya sentrifugal, minyak yang berat jenisnya (BJ) lebih kecil akan bergerak menuju poros dan terdorong keluar melalui sudut sudut ruang tangki pisah (separating tank). Sludge Separator ada terdiri atas: Low Speed (sering disebut juga Sludge Centrifuge) dan High Speed Separator.

Mesin ini adalah salah satu bagian dari mesin untuk proses pengolahan limbah pabrik kelapa sawit / proses pengolahan limbah cair pabrik kelapa sawit. Adapun cara kerjanya dapat dilihat pada gambar dibawah ini :

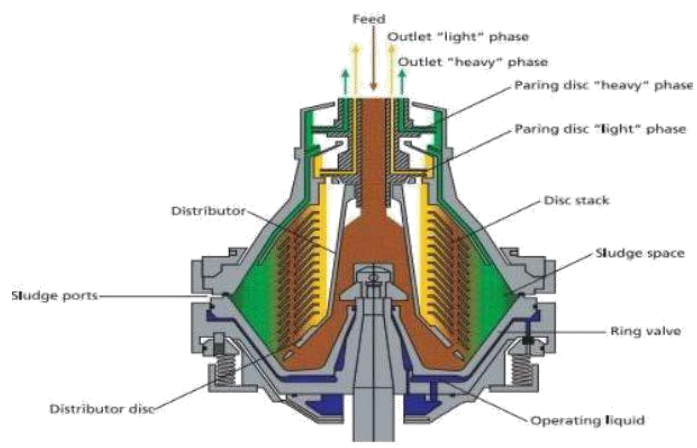

Gambar 1.1 Bagian dalam Sludge Separator

\section{TEORI DASAR}

\subsection{Sludge Seperator}

Sludge separator bekerja untuk memisahkan elemen padat dan cair. Model dari alat ini adalah sentrifugal dengan mangkuk berbentuk padat dan selalu berotasi selama proses pemisahan. Kinerjanya dengan memanfaatkan sistem putaran mangkuk yang telah dipasang dan dilepaskan keluar melalui discharge nozzle. Tingkat keberhasilan memisahkan minyak dari elemen padat akan tergantung dari kualitas alat yang digunakan. Dengan menggunakan wastewater sludge centrifuge, proses dalam pabrik kelapa sawit akan berjalan lebih lancar. Dimana sludge yang memiliki berat jenis (bj) > 1,0 (heavy phase) akan terlempar keluar sedangkan minyak yang memiliki berat jenis lebih ringan (light phase) akan terkumpul di tengah bowl melalui discharge pipe untuk dikirim kembali ke continuous settling tank. (Mesin PKS. 2020).

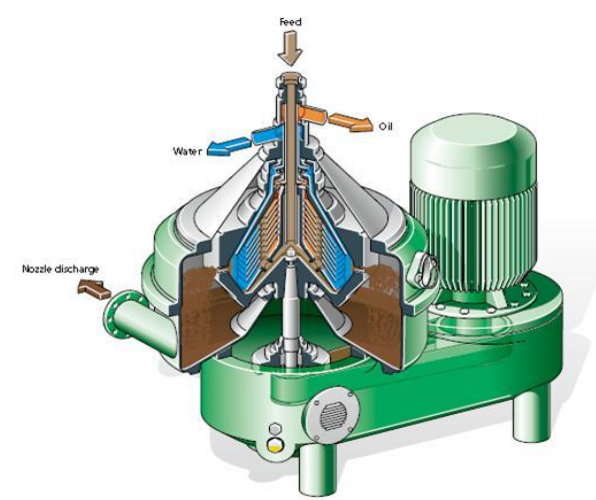

Gambar 2.1 Cara Kerja Sludge Separator 


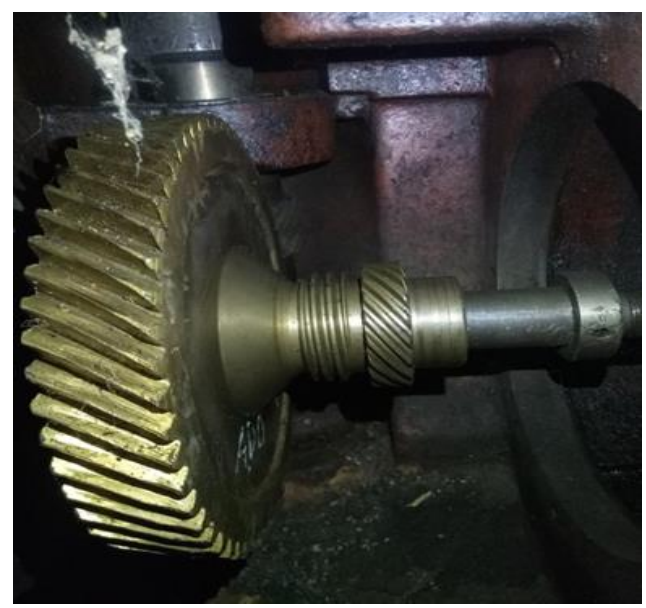

Gambar 2.2 Sistem Transmisi pada Sludge Seperator

\subsection{Jejak Kegagalan Sludge Seperator}

Ditunjukkan pada Gambar 2.2 worm gear mengalami keausan. Menurut Zainuri (2011) worm gears banyak digunakan untuk mentransmisikan daya pada rasio kecepatan yang tinggi antar poros yang secara umum tidak saling memotong. Rasio kecepatan worm gears mencapai $300: 1$ atau lebih tetapi mempunyai efisiensi yang rendah.

Berikut ini akan sedikit diuraikan jenis-jenis kerusakan akibat tegangan pada permukaan gigi akibat adanya beban geser yang berlebih :

a. SCUFFING (lecet)

Scuffing adalah goresan pada permukaan gigi dikarenakan efek las (welding effect ) dan gesekan dari sisi gigi yang kontak. Bentuknya seperti goresan garis melengkung. Ini terjadi ketika lapisan film oli sangat minim sehingga tidak mampu melapisi kekasaran permukaan dari gigi kontak dan gesekan metal ke metal pun terjadi. Scuffing muncul karena dua hal : Pertama adalah, gagalnya pelumas melapisi permukaan gigi sehingga terjadi kontak metal ke metal, Kedua adalah, panas yang tinggi pada saat terjadi kontak gigi.

b. WEAR (aus)

Aus dikategorikan sebagai hilang / berpindahnya logam dari permukaan gigi. Aus dapat mengurangi ketebalan modul gigi atau bahkan merubah bentuknya. Ini dapat terjadi akibat reaksi mekanik, elektrik, dan kimiawi. Kualitas oli pelumas sangat menentukan tingkat keausan dari permukaan gigi.

c. MICROPITTING (cacat kecil)

Micropitting adalah factor kelelahan (fatigue) akibat kontak gulung (rolling) berkecepatan tinggi. Karena ukurannya (yang kecil), jenis cacat ini sulit ditemukan (dengan mata telanjang)

\subsection{Getaran Vibrasi}

Getaran adalah suatu gerakan bolak - balik yang mempunyai amplitudo yang beragam (Rao,2004). Getaran biasa terjadi saat mesin atau alat dijalankan dengan motor, hal ini mempunyai pengaruh yang bersifat mekanis. Getaran merupakan gerak osilasi disekitar sebuah titik yang disebabkan oleh getaran udara atau mekanis, misalnya mesin atau alat - alat mekanis lainnya. Oleh sebab itu getaran banyak dipergunakan untuk menganalisis mesin-mesin baik dari gerak rotasi atau translasi. Grafik frekuensi vs hari ditunjukkan pada gambar 2.3.

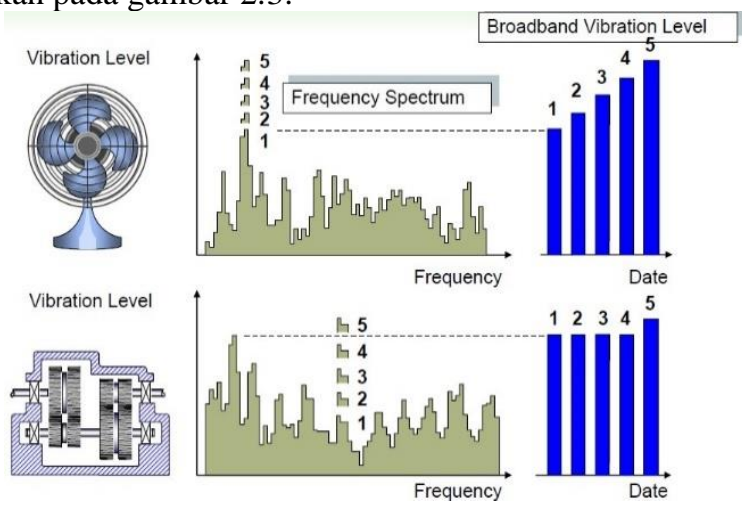

Gambar 2.3 Grafik Frekuensi vs Hari ${ }^{[2]}$ 


\subsection{Frekuensi Natural}

Dalam ilmu mekanika, ada sebuah istilah fisika yang disebut sebagai frekuensi natural (natural frequency). Fenomena yang berkaitan erat dengan frekuensi natural adalah peristiwa resonansi, yaitu ikut bergetarnya sebuah benda karena getaran benda lain di sekitarnya. Frekuensi natural adalah frekuensi dimana sistem berosilasi ketika sistem itu terganggu.

Frekuensi pribadi dipengaruhi oleh massa dan kekakuan. Kekakuan adalah sifat dari material. Pegas memiliki konstanta pegas $\mathrm{k}$, sedangkan material memiliki modulus elastisitas yang merupakan perbandingan tegangan regangan.

Frekuensi natural didefinisikan sebagai frekuensi pada saat sistem akan bergetar ketika mengalami getaran bebas. Pada waktu frekuensi yang bekerja pada sebuah mesin mendekati frekuensi natural fondasinya, amplitudo cenderung menjadi besar. Sistem dikatakan berada dalam keadaan resonansi ketika dua frekuensi tersebut menjadi sama. Pada resonansi ditemukan bahwa sebagai tambahan pada amplitudo yang berlebihan/lebih besar terjadi juga hasil yang besar. Frekuensi yang terjadi ketika nilai amplitudo mencapai nilai maksimum disebut frekuensi resonansi. Dalam desain permesinan, kriteria yang penting adalah menghindari resonansi dengan maksud bahwa amplitudo getaran kecil.

\subsection{Diagnosa Kegagalan Transmisi}

Diagnosa kegagalan pada transmisi dapat dilihat pada Gambar 2.4

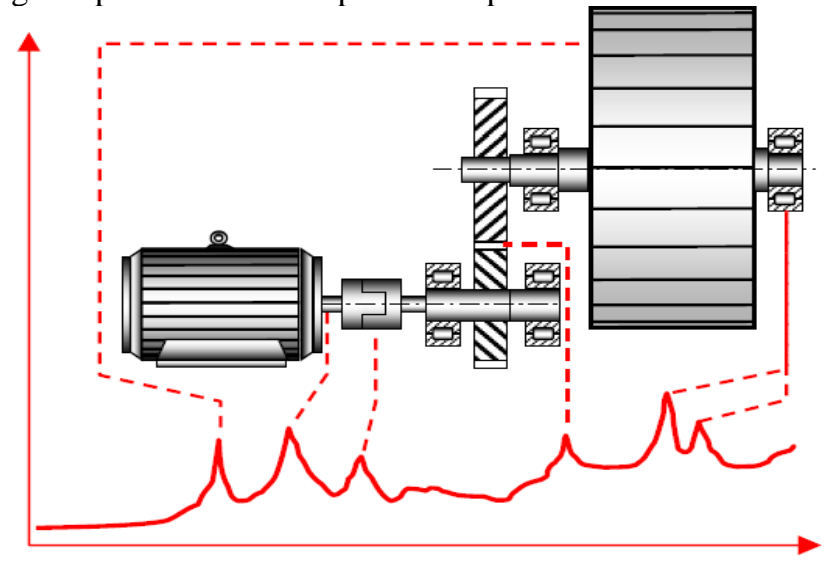

Gambar 2.4 Analisa Frekuensi Transmisi ${ }^{[4]}$ yaitu :

Kegagalan yang dapat terjadi pada worm gear sludge seperator yang diakibatkan oleh vibrasi

\section{Unbalance}

Unbalance adalah terjadinya pergeseran titik pusat massa dari titik pusat putarnya sehingga akan menimbulkan getaran yang tinggi. Dapat dilihat pada Gambar 2.5.

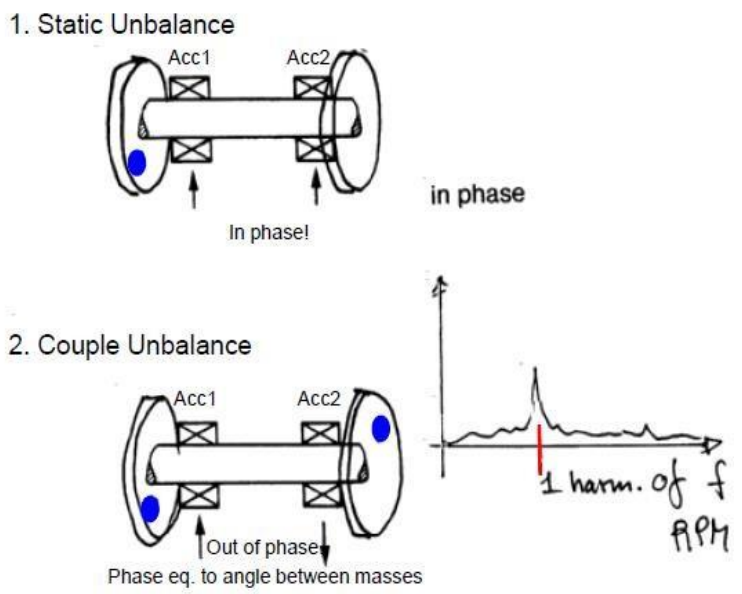

\section{Gambar 2.5 Unbalance ${ }^{[3]}$}

\section{Misalignment}

Vibrasi yang tinggi disebabkan oleh penyambungan poros yang tidak simetris dan besarannya tergantung dari ketidaksimetrisan penyambungannya, disebut Misalignment seperti pada Gambar 2.13. 


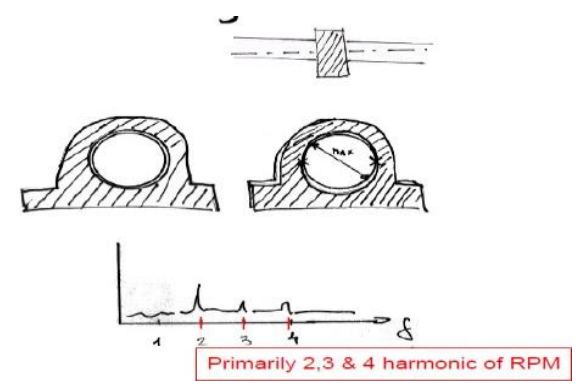

Gambar 2.13 Misalignment ${ }^{[3]}$

Pada gambar 2.14 dapat dilihat pengukuran missalignment pada transmisi dengan menggunakan transducer kecepatan.

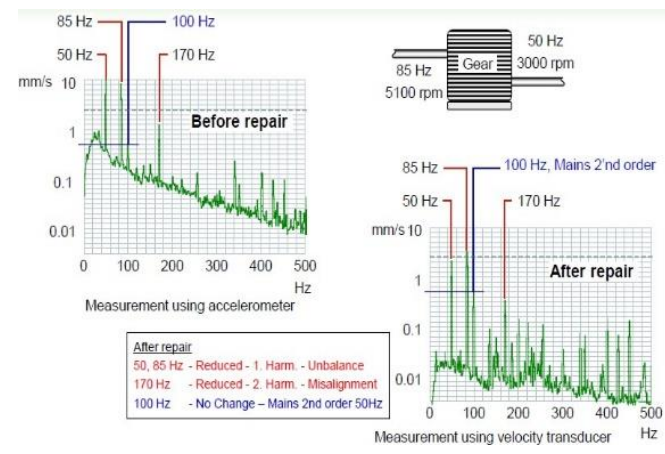

\section{HASIL DAN PEMBAHASAN \\ Gambar 2.14 Pengukuran Missalignment Worm Gear ${ }^{[3]}$}

Pada usulan penelitian ini, objek yang dianalisa adalah worm gear mesin sludge separator pada pabrik kelapa sawit. Objek mesin diamati dan dianalisa selama kurun waktu tertentu menggunakan alat komputasi dan eksperimental.

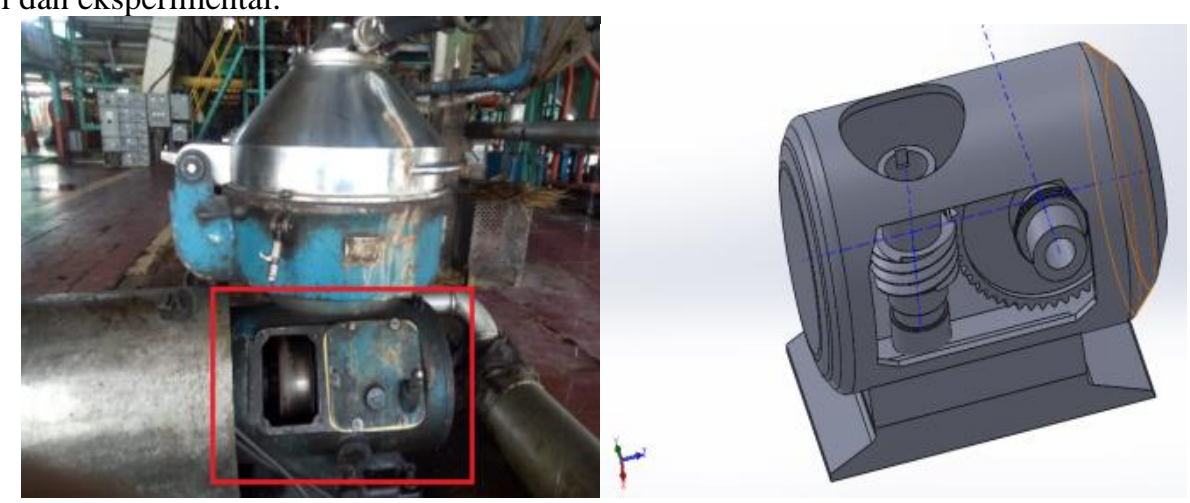

Gambar 3.1 Casing Sistem Transmisi Slugde Separator Sebagai Objek Penelitian

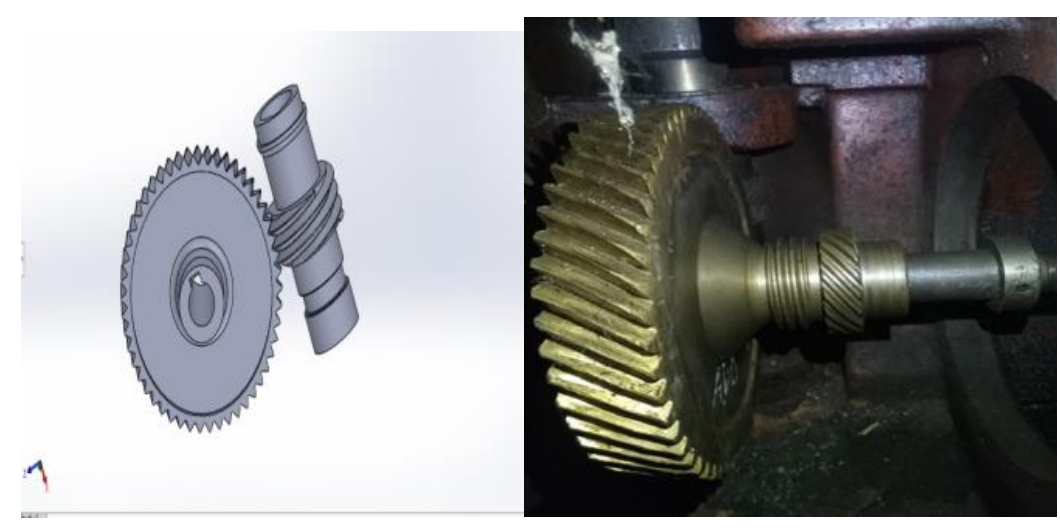

Gambar 3.2 Worm Gear Sludge Separator 
Untuk mengamati dan memprediksi getaran yang terjadi pada transmisi ,maka dilakukan dengan membangun kaidah numerik yang akan mensimulasikan frekuensi natural dan mode getar yang terjadi. Dalam penelitian ini kedua kaidah tersebut akan ditinjau untuk mendapatkan karakteristik getaran yang nyaman pada saat mesi beroperasi. Untuk itu langkah awal yang perlu dilakukan adalah mengidentifikasi desain parameter dari objek getaran yang akan diteliti.

\subsection{Desain Parameter Analisis (Design Of Analysis)}

Tabel komponen dan fungsi memaparkan detail bagian penelitian mana yang difokuskan untuk dilakukan peninjauan, hal ini mencakup komponen apa saja yang diteliti, fungsi dari komponen dalam sistem, perubahan fenomena fisik yang dialami komponen, parameter yang ditinjau dalam komponen serta menetapkan rumus empirik yang digunakan dalam membahas perubahan parameter yang dialami komponen.

Komponen yang akan dibahas hanya mencakup bagian transmisi dikarenakan pada transmisi terjadi putaran dan kontak antar roda gigi sehingga dapat melahirkan getaran. Komponen - komponen yang berada didalam sistem transmisi menjadi acuan penelitan karena merupakan didalam sistem transmisi terdapat komponen yang kompleks dan bergesekan antar roda gigi. Frekuensi natural dan mode getar yang terjadi dijadikan sebagai tolak ukur getaran dalam transmisi. Perbedaan hasil antara setiap sistem dikarenakan perbedaan kontak ketika pergantian transmisi dilakukan. Pada tabel 3.1 ditunjukkan komponen dan fungsi yang diteliti.

Tabel 3.1 Komponen Material Worm Gear Sludge Separator

\begin{tabular}{|c|c|c|c|}
\hline \multirow{2}{*}{ No. } & \multicolumn{2}{|c|}{ Material } & $\begin{array}{c}\text { Load stress } \\
\text { factor } \\
(\mathrm{K}) \mathrm{N} / \mathrm{mm}^{2}\end{array}$ \\
\cline { 2 - 3 } & Worm & Worm gear & 0.415 \\
\hline 1 & Steel (B.H.N.250) & $\begin{array}{c}\text { Phosphor } \\
\text { bronze }\end{array}$ & 0.345 \\
\hline 2 & Hardened steel & Cast iron & 0.550 \\
\hline 3 & Hardened steel & $\begin{array}{c}\text { Phosphor } \\
\text { bronze }\end{array}$ & $\begin{array}{c}\text { Chilled } \\
\text { phosphorbro } \\
\text { nze }\end{array}$ \\
\hline 4 & Hardened steel & $\begin{array}{c}\text { Antimony } \\
\text { bronze }\end{array}$ & 0.830 \\
\hline 5 & Hardened steel & $\begin{array}{c}\text { Phosphor } \\
\text { bronze }\end{array}$ & 1.035 \\
\hline 6 & Cast iron & \multicolumn{2}{|c|}{} \\
\hline
\end{tabular}

Sifat mekanik material yang digunakan dalam analisis adalah sebagai berikut :

1. Roda gigi: Gray cast iron

Modulus Elastisitas $(\mathrm{E})=1,1 \mathrm{E}+11 \mathrm{~Pa}$

Poisson ratio $=0,28$

Densitas $=7.200 \mathrm{~kg} \mathrm{~mm}^{-3}$

2. Bantalan : Bearing steel (Sumber: AHR Internasional)

Modulus Elastisitas $(\mathrm{E})=2,08 \mathrm{E}+11 \mathrm{~Pa}$

Poisson ratio $=0,3$

Densitas $=7,85 \mathrm{~g} \mathrm{~cm}^{-3}$

3. Roda gigi cacing dan poros : Mild steel

Modulus Elastisitas $(\mathrm{E})=2,1 \mathrm{E}+11 \mathrm{~Pa}$

Poisson ratio $=0,303$

Densitas $=7.850 \mathrm{~kg} \mathrm{~mm}^{-3}$

Gray cast iron merupakan bahan dengan peredam dipilih sebagai material worm gear Sifat material seperti modulus elastisitas, poisson ratio dan densitas diperlukan untuk analisis vibrasi. Gray cast iron memiliki modulus elastisitas sebesar $1,1 \mathrm{E}+11 \mathrm{~Pa}$; poisson ratio 0,28 dan densitas $7.200 \mathrm{~kg} \mathrm{~mm}^{-}$ ${ }^{3}$ (Sumber: Ansys). Material roda gigi (worm gear) dan bearing menggunakan mild steel dengan modulus elastisitas sebesar 2,1E+11 Pa; poisson ratio 0,303 dan densitas $7.850 \mathrm{~kg} \mathrm{~mm}^{-3}$ (Sumber: Ansys). Material untuk bantalan digunakan bearing steel dengan modulus elastisitas sebesar 2,08E+11 $\mathrm{Pa}$; poisson ratio 0,3 dan densitas 7,85 $\mathrm{g} \mathrm{cm}^{-3}$ (Sumber: AHR Intenasional). Kondisi batas yaitu berupa konstrain tanpa perpindahan diberlakukan dalam casing. Fixed support diberikan di bawah, di kiri dan di kanan. Dapat dilihat pada gambar 3.3 posisi diletakkan fixed support. Frictionless support diletakkan pada bantalan sebagai tempat bergantungnya poros sludge seperator. 


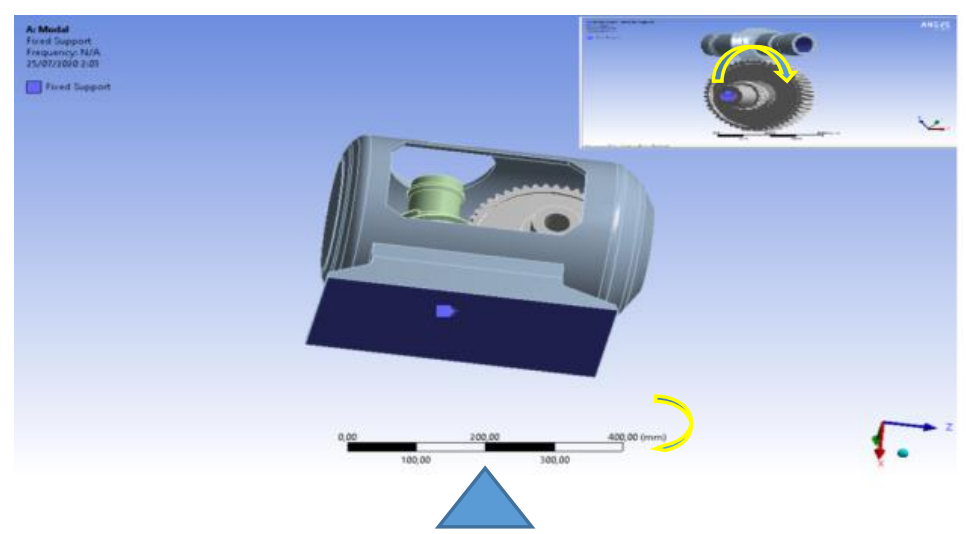

Gambar 3.3 Proses Input Kondisi Batas pada Sistem Transmisi

$=$ Fix support

p = Momen inersia

\subsection{Hasil Simulasi}

Pada modal analisis beban yang diberikan diatur secara otomatis dari program, dengan menetapkan kondisi batas.

\subsubsection{Frekuensi natural Pada Worm Gear Sludge Seperator}

1. Frekuensi natural pada putaran $1000 \mathrm{RPM}$

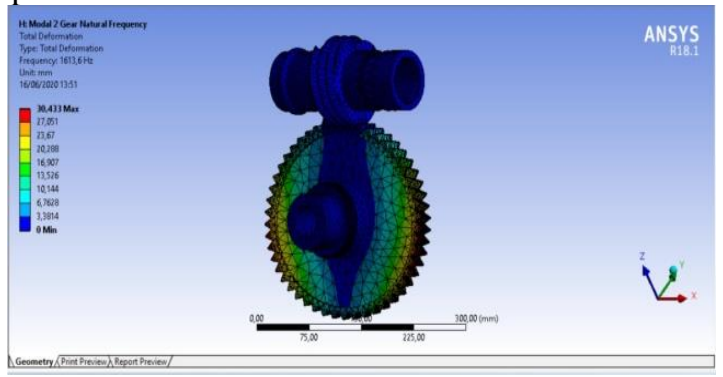

Gambar 3.4 Fn (1613,6 Hz)

Pada gambar 3.4 merupakan mode pertama dengan putaran $1000 \mathrm{rpm}$. Dapat dilihat terjadi frekuensi natural sebesar 1613,6 Hz. Mode getar yang terjadi yaitu terjadi vibrasi aksial defleksi pada roda gigi bawah dan torsional pada sistem. Vibrasi yang terjadi dapat menyebabkan beban impact terjadi antara poros output dengan poros input. Beban impact yang berlebihan dapat menyebabkan kegagalan transmisi.

2. Frekuensi natural pada putaran 2000 RPM

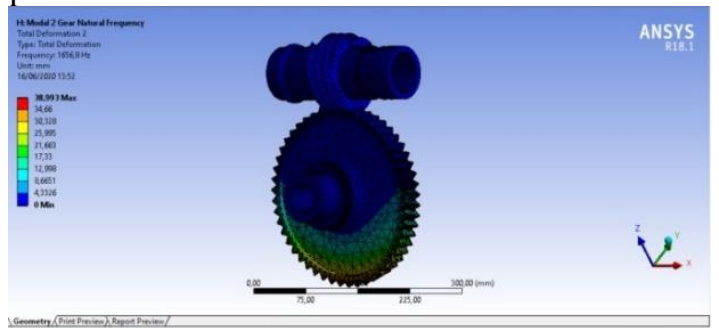

Gambar 3.5 Fn (1656,8 Hz)

Pada gambar 3.5 merupakan mode ke-dua dari. Dapat dilihat terjadi frekuensi natural sebesar 1656,8 Hz. Mode getar yang terjadi yaitu terjadi vibrasi aksial defleksi pada gear bawah dan torsional pada sistem. Resonansi getaran yang terjadi dapat mengakibatkan kegagalan dalam transmisi.

3. Frekuensi natural pada putaran 3000 RPM 


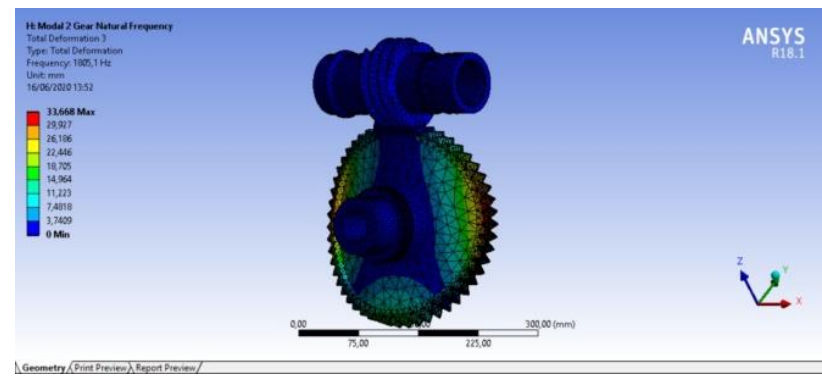

Gambar 3.6 Fn (1805,1 Hz)

Pada gambar 3.6 merupakan mode ketiga. Dapat dilihat terjadi frekuensi natural sebesar 1805,1 Hz. Mode getar yang terjadi yaitu vibrasi aksial defleksi pada gear bagian luar. Getaran yang terjadi menyebabkan resonansi pada bagian poros input. Mode getar yang terjadi seperti ini dapat menyebabkan tidak sejajarnya poros ketika bekerja.

4. Frekuensi natural pada putaran 4000 RPM

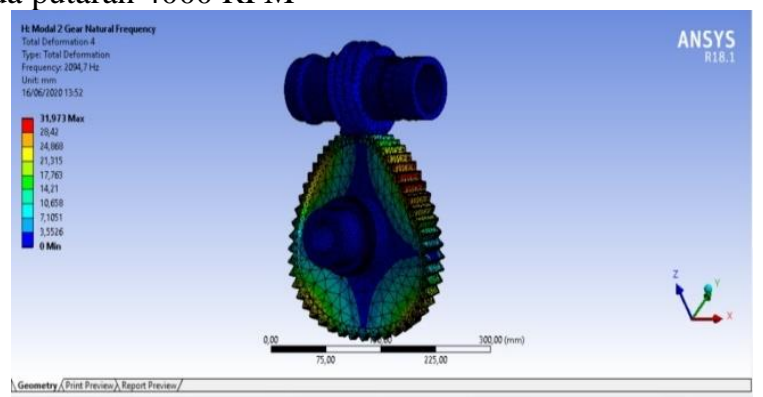

Gambar 3.7 Fn (2094,7 Hz)

Pada gambar 3.7 merupakan mode keempat. Dapat dilihat terjadi frekuensi natural sebesar 2094,7 Hz. Mode getar yang terjadi yaitu vibrasi aksial defleksi. Getaran yang terjadi dapat mengakibatkan poros tidak sejajar.

5. Frekuensi natural pada putaran 5000 RPM

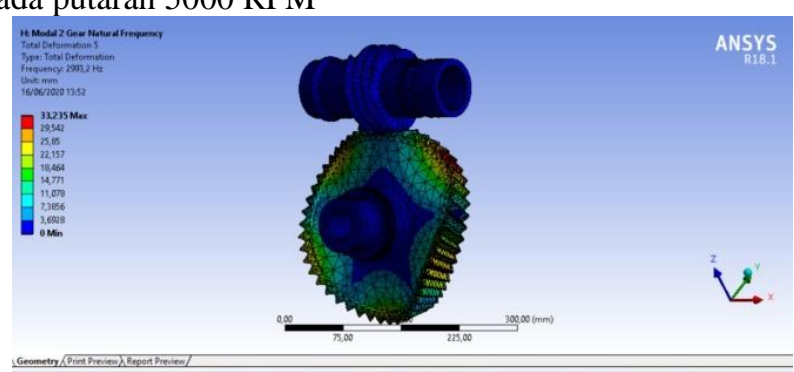

\section{Gambar 3.8 Fn $(2993,2 \mathrm{~Hz})$}

Pada gambar 3.8 Merupakan mode kelima. Dapat dilihat terjadi frekuensi natural sebesar 2993,2 Hz. Mode getar yang terjadi yaitu getaran berupa defleksi pada hampir semua bagian gear. Vibrasi yang terjadi dapat menyebabkan beban impact terjadi antara casing dengan transmisi yang berada didalamnya. 6. Frekuensi natural pada putaran 6500 RPM

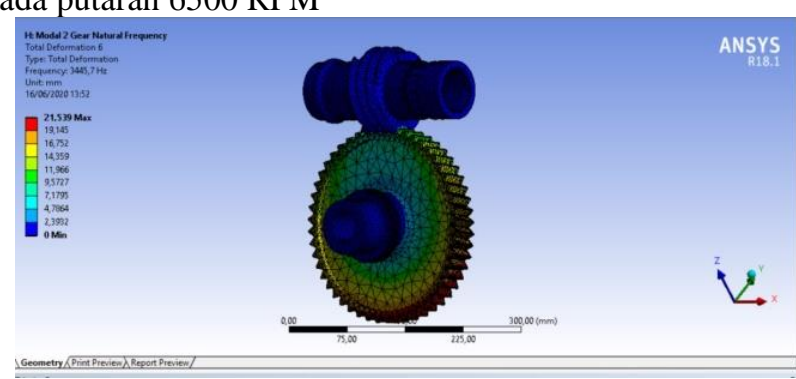

Gambar 3.9 Fn $(3445,7$ Hz) 
Pada gambar 3.9 Merupakan mode keenam. Dapat dilihat terjadi frekuensi natural sebesar 3445,7 Hz. Mode getar yang terjadi yaitu getaran berupa defleksi pada seluruh gear. Vibrasi yang terjadi dapat menyebabkan beban impact terjadi antara casing dengan transmisi yang berada didalamnya.

\subsubsection{Frekuensi Natural Pada Casing Sludge Seperator}

Pada worm gear dapat dilihat jenis getaran dan frekuensi natural yang terjadi sebesar $(138,26-$ 651,66) Hz. Dapat dilihat pada gambar - gambar tiap mode (titik pengukuran eksperimental berdasarkan rujukan komputasional) yang terjadi pada worm gear pada 1000-6500 rpm

1. Sistem transmisi sludge seperator percobaan pertama(1000 RPM)

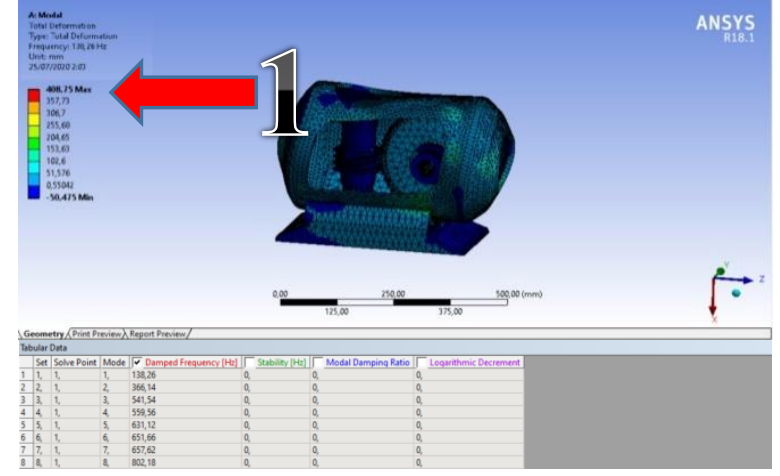

Gambar 3.10 Mode $1(\mathbf{f} 1=138,26 \mathrm{~Hz})$

Dapat dilihat pada gambar 3.10 merupakan percobaan pertama dari worm gear terjadi frekuensi natural sebesar 138,26 Hz. Frekuensi yang didapat 138,26-802,18 Hz. Mode getar yang terjadi pada mode pertama yaitu terjadi vibrasi aksial defleksi pada poros input. Dimana deformasi terbesar terjadi pada bagian gigi gigi transmisi dan menyebabkan resonansi getaran menjalar ke bagian poros input. Mode getar yang terjadi seperti ini dapat menyebabkan tidak sejajarnya poros ketika bekerja.

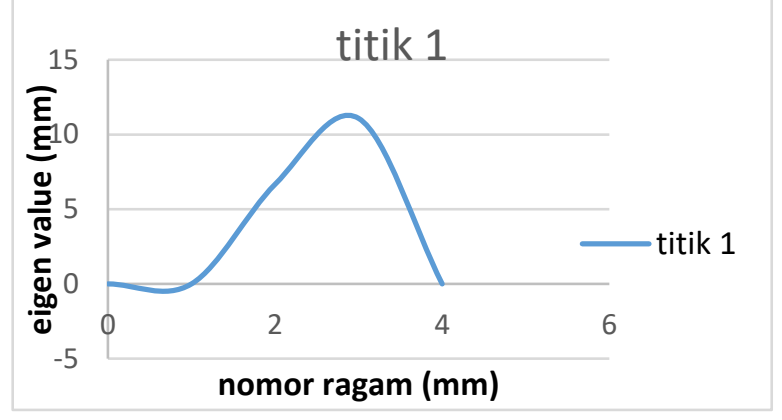

Gambar 3.11 Grafik Eigen Value Pada Titik Pertama

Gambar 3.11 menunjukkan titik gelombang tertinggi (eigen value) berada pada 11,3 mm pada posisi nomor ragam sekitar $2,9 \mathrm{~mm}$

2. Sistem transmisi sludge seperator percobaan kedua

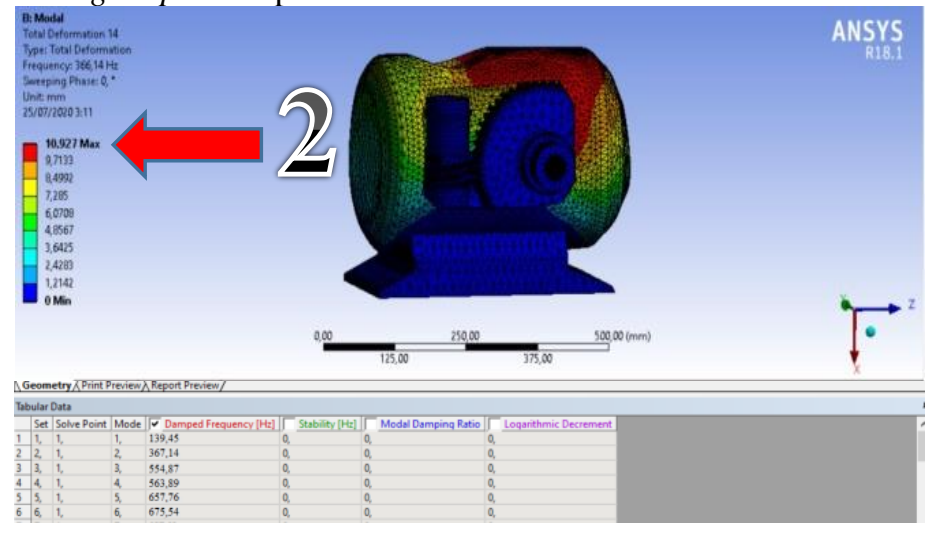

Gambar 3.12 Mode (f2=541,54 Hz)

Pada gambar 3.12 merupakan mode kedua. Dapat dilihat terjadi frekuensi natural sebesar 559,56 
Hz. Frekuensi yang didapat 139,45-675,54 Hz. Mode getar yang terjadi pada mode kedua yaitu vibrasi aksial defleksi. Getaran yang terjadi menyebabkan resonansi pada bagian casing sludge seperator.

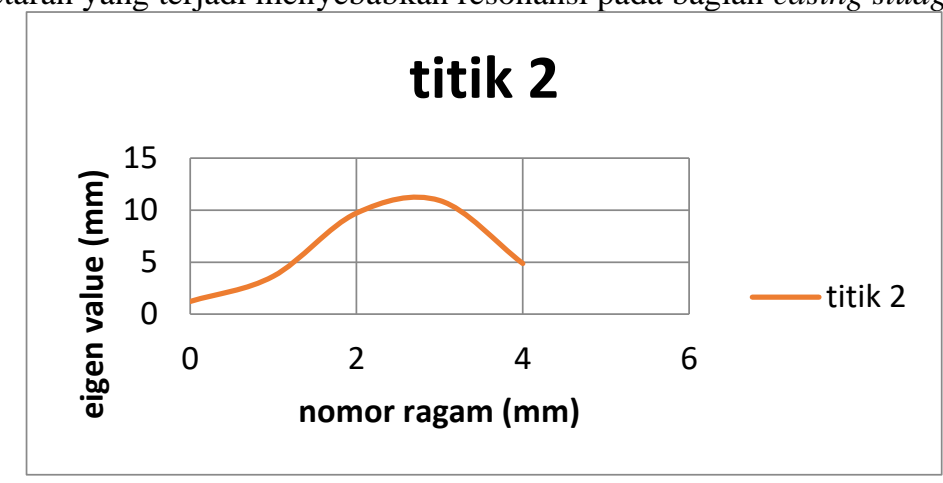

\section{Gambar 3.13 Grafik Eigen Value Pada Titik Kedua}

Gambar 3.13 menunjukkan grafik titik gelombang tertinggi (eigen value) berada pada $11,2 \mathrm{~mm}$ pada posisi nomor ragam sekitar 2,6 $\mathrm{mm}$

3. Sistem transmisi sludge seperator percobaan ketiga

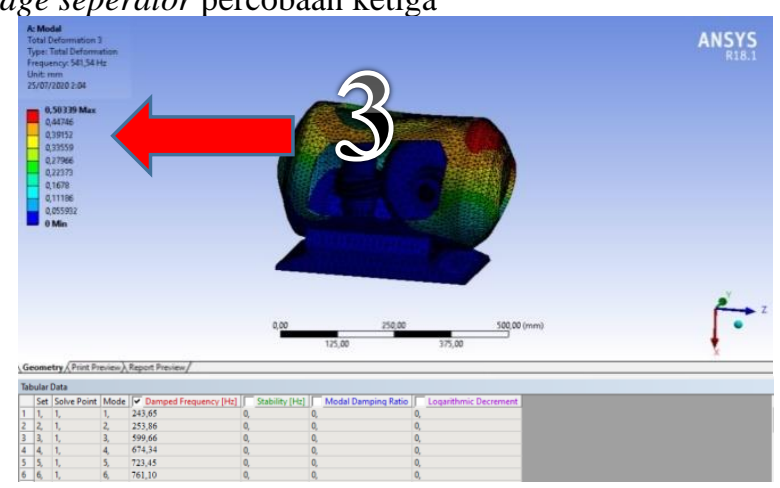

Gambar 3.14 Mode (f3 =541,54 Hz)

Pada gambar 3.14 Merupakan mode ketiga dari sistem transmisi sludge seperator. Dapat dilihat terjadi frekuensi natural sebesar 541,54 Hz. Frekuensi yang terjadi berdasarkan ragam putaran 243,65761,10 Hz. Mode getar yang terjadi yaitu getaran berupa defleksi pada casing bagian atas.

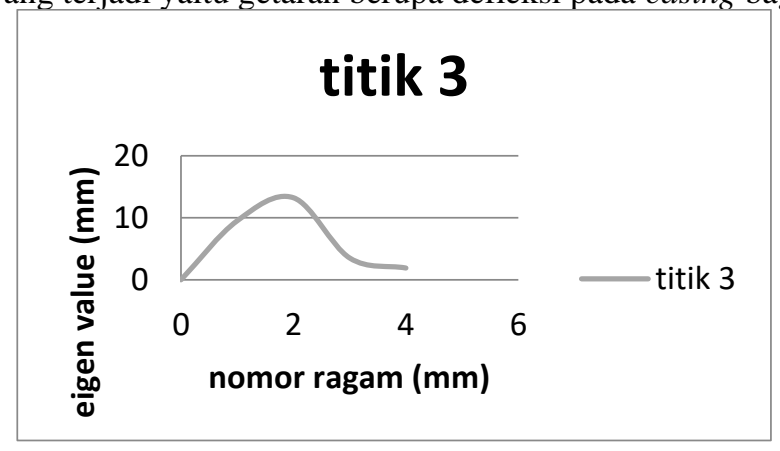

Gambar 3.15 grafik eigen value pada titik ketiga

Gambar 3.15 menunjukkan grafik titik gelombang tertinggi (eigen value) berada pada 13,6 mm pada posisi nomor ragam sekitar $1,9 \mathrm{~mm}$

4. Sistem transmisi sludge seperator percobaan keempat 


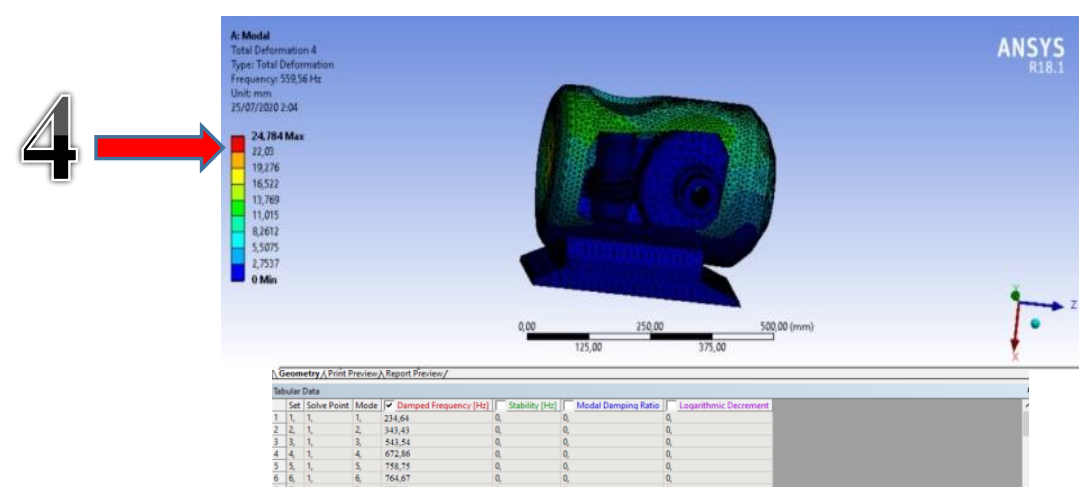

\section{Gambar 3.16 Mode (f4 559,56 Hz)}

Pada gambar 3.16 Merupakan mode ke-empat dari worm gear. Dapat dilihat terjadi frekuensi natural sebesar 559,56 Hz. Damped frekuensi sebesar 234,64-764,67 Hz. Mode getar yang terjadi yaitu vibrasi aksial defleksi pada casing sludge seperator dan terjadi vibrasi torsional dari sistem. Deformasi terbesar terjadi pada bagian luar casing

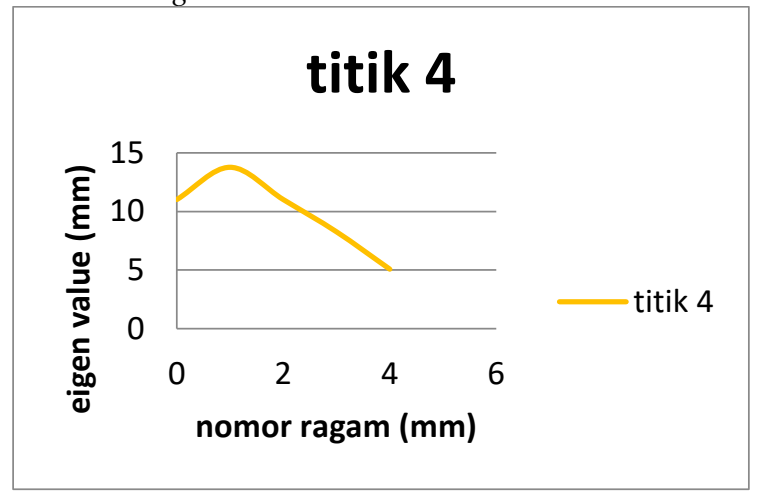

\section{Gambar 3.17 Grafik Eigen Value Pada Titik Keempat}

Gambar 3.17 menunjukkan grafik titik gelombang tertinggi (eigen value) berada pada 13,9 mm pada posisi nomor ragam sekitar $1,1 \mathrm{~mm}$

5. Sistem transmisi sludge seperator percobaan kelima

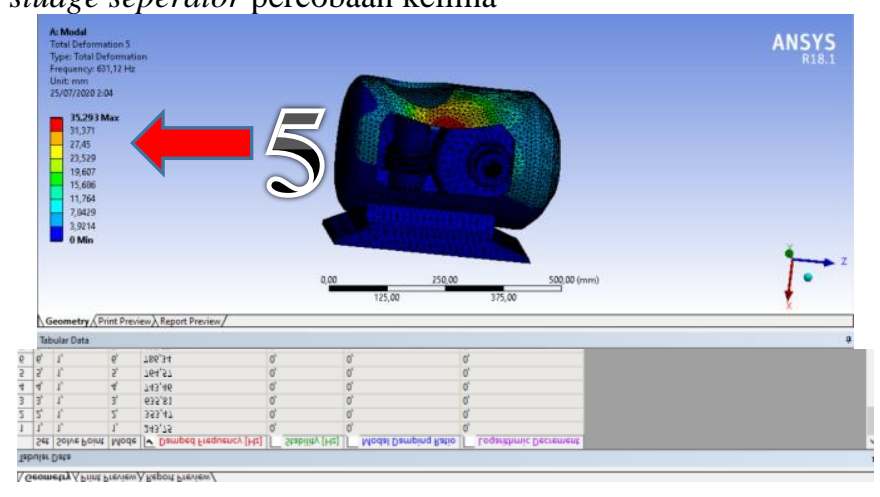

Gambar 3.18 Mode $5(\mathrm{f5}=631,12 \mathrm{~Hz})$

Pada gambar 3.18 merupakan mode ke-lima dari worm gear. Dapat dilihat terjadi frekuensi natural sebesar 631,12 Hz. Damped frekuensi 243,75-786,34 Hz. Mode getar yang terjadi yaitu getaran berupa defleksi pada casing bagian tengah atas. Vibrasi yang terjadi dapat menyebabkan total deformasi yang menyebabkan resonansi pada worm gear. 


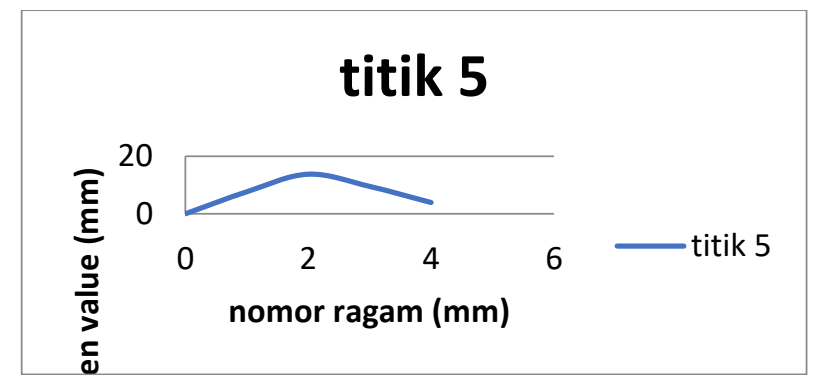

Gambar 3.19 Grafik Eigen Value Pada Titik Kelima

Gambar 3.19 menunjukkan grafik titik gelombang tertinggi (eigen value) berada pada 13,99 mm pada posisi nomor ragam sekitar 2,02 $\mathrm{mm}$

6. Sistem transmisi sludge seperator percobaan keenam
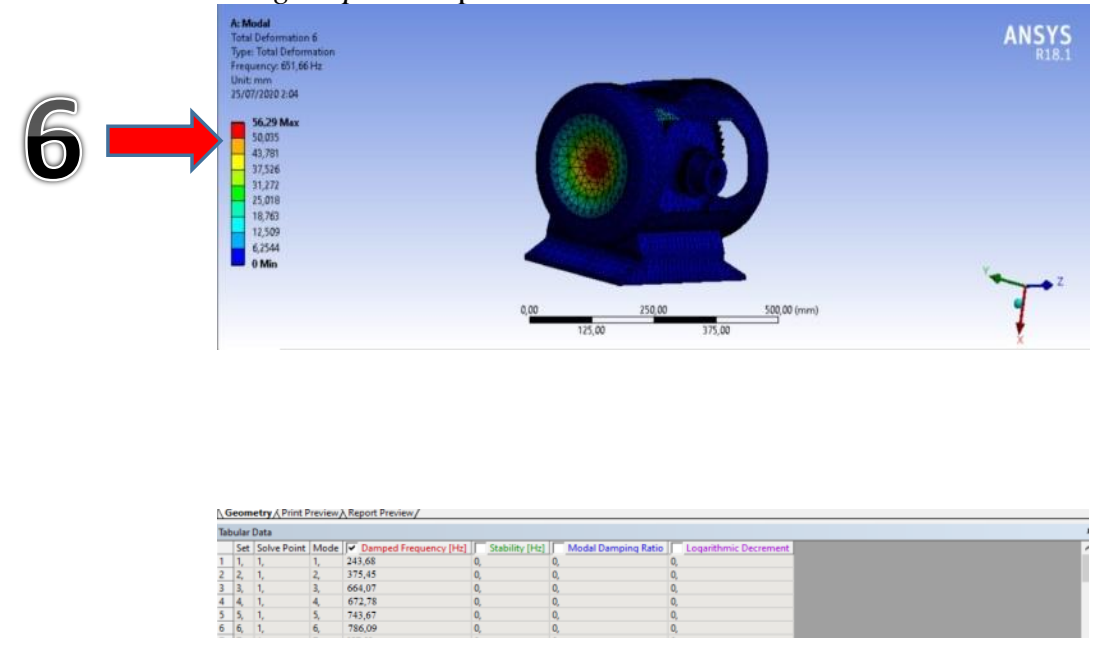

Gambar 3.20 Mode 6 (f5 =651,66 Hz)

Pada gambar 3.20 merupakan mode ke-enam dari worm gear. Dapat dilihat terjadi frekuensi natural sebesar 651,66 Hz. Damped frekuensi 243,68-786,09 Hz. Mode getar yang terjadi yaitu vibrasi aksial defleksi pada poros output dan terjadi getaran torsional yang minim pada sistem. Getaran yang terjadi paling signifikan pada belakang casing worm gear. Getaran yang terjadi dapat mengakibatkan tidak sejajarnya poros.

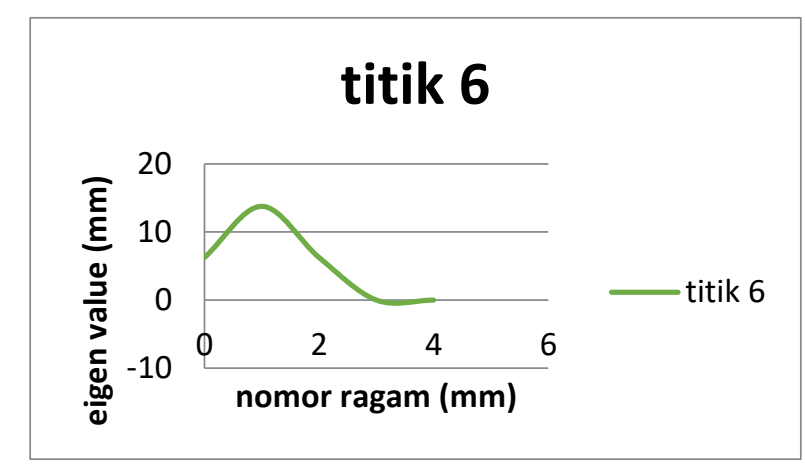

Gambar 3.21 Grafik Eigen Value Pada Titik Keenam

Gambar 3.21 menunjukkan grafik titik gelombang tertinggi (eigen value) berada pada 13,8 mm pada posisi nomor ragam sekitar $1,1 \mathrm{~mm}$ 


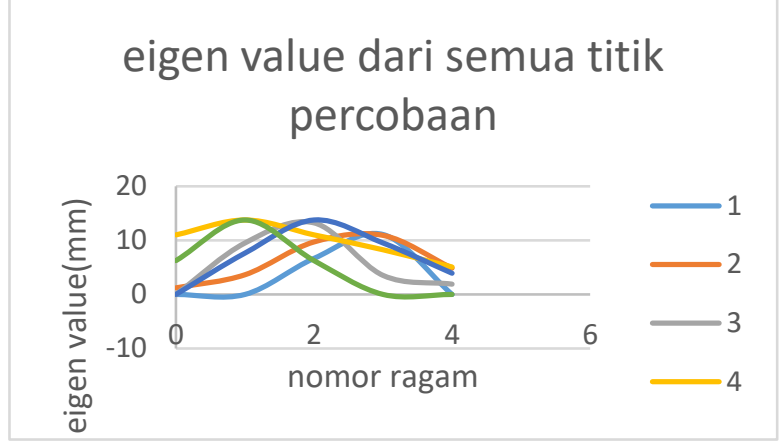

Gambar 3.22 Grafik Eigen Value Dari Semua Titik Percobaan

Gambar 3.22 menunjukkan grafik dari ragam mode berbanding dengan eigen value yang menunjukkan pada semua sistem percobaan pada casing sludge separator. Grafik gelombang pada percobaan 6 menunjukkan gelombang dari eigen value berada pada titik paling atas sedangkan pada titik ter-rendah ditunjukan pada grafik gelombang eigen value pada percobaan kedua dimana setiap grafik gelombang dari setiap percobaan bervariasi sesuai dengan hasil nilai frekuensi yang didapat dari hasil simulasi pada sistem transmisi beserta casing.

\section{KESIMPULAN DAN SARAN}

\subsection{Kesimpulan}

Berdasarkan hasil simulasi dari analisis, maka dapat diambil kesimpulan dari hasil penelitian ini yaitu:

1. Pada simulasi dihasilkan frekuensi natural sebesar pada sistem transmisi titik pertama dengan kecepatan putar $(1000-6500 \mathrm{rpm})$ adalah $(138,26-651,66) \mathrm{Hz}$, sistem transmisi pada titik kedua $(139,45-675,54) \mathrm{Hz}$, sistem transmisi pada titik ketiga $(234,65-761,10) \mathrm{Hz}$, sistem transmisi pada titik keempat $(243,64-764,67) \mathrm{Hz}$, sistem transmisi pada titik kelima $(243,75-786,34) \mathrm{Hz}$, sistem transmisi pada titik keenam $(243,68-786,09) \mathrm{Hz}$.

2. Vibrasi tertinggi terjadi pada worm gear sludge separator pada titik ke enam dengan kecepatan putar roda gigi menuju bowl disck sebesar 6500 rpm berada pada rentang 243,68-786,09 Hz. Dikarenakan roda gigi mengalami perputaran tertinggi pada simulasi dan terjadi lebih banyak kontak antar gigi sehingga massa dari roda gigi menjadi lebih berat.

3. Moda getar yang terjadi pada casing berupa getaran defleksi, pada transmisi terjadi getaran aksial defleksi dan torsional. Pada 6 posisi defeleksi seperti pada Gambar 3.4 sampai 3.9

4. Setelah dilakukan simulasi, didapatkan hasil resultan velocity amplitudo dan frekuensi natural cenderung lebih tinggi dibandingkan dengan eksperimental dikarenakan kondisi desain dari transmisi dalam keadaan ideal. Dimana hasil resultan velocity amplitudo eksperimental 1.000-6500 RPM system transmisi titik satu 2,001 mm/s; sistem transmisi titik dua $2,215 \mathrm{~mm} / \mathrm{s}$; sistem transmisi titik tiga $4,798 \mathrm{~mm} / \mathrm{s}$; sistem transmisi titik empat $5,436 \mathrm{~mm} / \mathrm{s}$; sistem transmisi titik lima $5,67 \mathrm{~mm} / \mathrm{s}$ dan sistem transmisi titik enam $5,721 \mathrm{~mm} / \mathrm{s}$. Sedangkan hasil simulasi pada sistem transmisi titik satu $3,315 \mathrm{~mm} / \mathrm{s}$; sistem transmisi titik dua $4,915 \mathrm{~mm} / \mathrm{s}$; sistem transmisi titik tiga $5,585 \mathrm{~mm} / \mathrm{s}$; sistem transmisi titik empat $5,315 \mathrm{~mm} / \mathrm{s}$; sistem transmisi titik lima $5,915 \mathrm{~mm} / \mathrm{s}$ dan sistem transmisi titik enam $6,315 \mathrm{~mm} / \mathrm{s}$.

\subsection{Saran}

Berdasarkan hasil simulasi yang dilakukan, saran yang dapat diberikan dari peneliti adalah sebagai berikut :

1. Melakukan penelitian selanjutnya, yaitu pada bagian bowl disck sludge separator dikarenakan lebih rentan terhadap bagian tersebut.

2. Sebaiknya dapat juga ditambahkan pelumasan dalam melakukan simulasi.

3. Untuk penelitian selanjutnya data eksperimental dari transmisi sebaiknya dilakukan eksperimental dengan menggunakan test rig.

\section{REFERENSI}

[1] Meirovitch, 1., Manual Book Sludge Seperator, Components Sludge Seperator, McGraw-Hill, New York, 1970 
[2] Fu, Z.F. He, J. (2001). Modal Analysis. Butterworth-Heinemann, Oxford. Krodkiewski.J.M. (2008). Mechanical Vibration. The University of Melbourne, Department of Mechanical and Manufacturing Engineering.

[3] Pennock. G. R, Shigley. J. E, Uicker.J.J. (2003). Theory of Machines and Mechanisms (3rd ed.). New York: Oxford University Press. ISBN 9780195155983.

[4] Strang, G. and Fix, G. I., An Analysis of the Finite Element Method, Prentice-Hall, Englewood Cliffs, NJ, 1973

[5] Turner, M.I., Clough, R.W. Marthin, H.C. and Topp, L.,' 'Stiffnes and Defflection Analysis of Complex Structures,' Journal of Aeronautical Sciences, Vol. 23,1956, pp.805-823

[6] Crandal, S. H. and Mark, W. D., Random Vibration in Mechanical Systems, Academic Press, Inc., New York, 1963

[7] Mathews, J. h., Numerical Methods for Computer Science, Engineering, and Mathematics, $2^{\text {nd }}$ ed., Prentice Hall, Englewood Cliffs, NJ, 1992.

[8] Bendat, J. S. and Piersol, A. G., Random: Analysis and Measurement Procedures, WileyInterscience, Newyork, 1971

[9] Patil, M. S., Patil, J. G. (2015). Vibration Analysis of Gearbox Casing using Software tool ANSYS and FFT Analyze. Volume 3, IJRAME. p.: 12-19.

[10] Shrenik M. Patil, Prof. S. M. Pise. (2013). Modal and Stress Analysis of Differential Gearbox Casing with Optimization.Volume 3, Ijera. p.:188-193

[11] Surbakti, Prakarsa (2020). Deteksi Dini Kegagalan pada Transmisi sludge seperator dengan Menggunakan Analisis Vibrasi. Fakultas Teknik USU. p.: 28-65.

[12] Walpole, Ronald E. (1993). Pengantar Statistika. Jakarta : PT Gramedia Pustaka Utama. 